Check for updates

Cite this: RSC Adv., 2017, 7, 46505

Received 28th July 2017

Accepted 15th September 2017

DOI: $10.1039 / \mathrm{c} 7 \mathrm{ra0} 8340 \mathrm{~h}$

rsc.li/rsc-advances

\section{Synergistic charring effect of triazinetrione-alkyl- phosphinate and phosphaphenanthrene derivatives in epoxy thermosets}

\begin{abstract}
Youyou Fang, ${ }^{\text {abc }}$ Lijun Qian, (DD *abc Zhigang Huang, ${ }^{\text {abc }}$ Shuo Tang ${ }^{\text {abd }}$ and Yong Qiu ${ }^{\text {abd }}$
A flame retardant tri-3-(aluminum phosphinate)-propyl-1-triazine-trione (TAHP) was synthesized via the addition reaction between triallyl isocyanurate (TAIC) and hypophosphorous acid, and the molecular structure and thermal stability of TAHP were characterized. Then, TAHP was applied to the diglycidyl ether of bisphenol A (EP) cured using 4,4'-diamino-diphenylmethane with another DOPO derivative TAD, and the synergistic flame-retardant behavior of TAHP/TAD and the mechanism of action were also investigated. Compared with 4\% TAHP/EP and 4\% TAD/EP samples, the sample with $1 \mathrm{wt} \%$ TAHP and 3 wt\% TAD obtained an LOI value of $36.0 \%$, passed the UL94 V-0 rating test and exhibited a decreased peak value of the heat release rate. The interaction of TAHP and TAD locked more phosphoruscontaining components in the residue and formed a phosphorus-rich char layer mixed with aluminum phosphate, which generated a synergistic charring effect between TAHP and TAD and brought a better barrier effect to the epoxy thermosets during combustion. The interaction between TAHP and TAD led to a more balanced flame retardancy in the gaseous phase and condensed phase. Therefore, the TAHP/ TAD system was able to endow epoxy thermosets with better flame retardancy than them used alone.
\end{abstract}

\section{Introduction}

As an important thermosetting resin, epoxy resin has been widely manufactured in adhesives, coatings and sealants for various applications. It has numerous advantages such as interface adhesion, sealing, corrosion resistance, electrical insulation and mechanical performance. ${ }^{\mathbf{1 - 4}}$ However, epoxy resins with low limit oxygen index value and poor UL94 rating are flammable and do not tend to self-extinguish once ignited. Moreover, excellent flame-retardant properties are often necessary for epoxy resins in most fields of application. Therefore, more and more attention has been aroused and the higher flame retardancy of epoxy resins has been required..$^{5-8}$

Recently, flame retardants containing the triazine group such as melamine cyanurate and melamine polyphosphate with good performance and low toxicity have been investigated. ${ }^{\mathbf{9}, 10}$ These compounds were widely used in flame-retarding epoxy resins, polyamides and polyesters. Usually, the triazine and triazine-trione groups exert a gas dilution effect in the gaseous

\footnotetext{
${ }^{a}$ School of Materials Science \& Mechanical Engineering, Beijing Technology and Business University, Beijing 100048, PR China. E-mail: qianlj@th.btbu.edu.cn

${ }^{b}$ Engineering Laboratory of Non-halogen Flame Retardants for Polymers, Beijing 100048, PR China

${ }^{c}$ Beijing Key Laboratory of Quality Evaluation Technology for Hygiene and Safety of Plastics, Beijing 100048, PR China

${ }^{d}$ School of Materials Science and Engineering, Beijing Institute of Technology, 5 South Zhongguancun Street, Beijing 100081, PR China
}

phase. ${ }^{11,12}$ In contrast to other typical flame-retardant groups, triazine or triazine-trione groups do not have strong flameretardant effect in polymers. However, when they are combined with other flame-retardant groups such as phosphaphenanthrenes, ${ }^{13-16}$ phosphates, and ethylpiperazines, ${ }^{17}$ the novel flame retardants usually possess group synergistic effects and endow better flame retardancy to the polymers. Inspired by this thought, we intended to design novel triazine molecules with other flame-retardant groups..$^{\mathbf{1 8 - 2 0}}$

Normally, phosphinate can endow epoxy resin with good flame retardancy and is widely used in polymeric materials. ${ }^{21-24}$ The noted product, aluminum diethylphosphinate, was first designed and synthetized by the Clarinet Company. ${ }^{25}$ Moreover, the compound was first prepared and commercialized by the Clariant Corporation, and it was found to work well in polymeric materials such as polyamides, polyesters and epoxy resins. ${ }^{26-29}$ It has been proven that metal phosphinate can bring outstanding flame retardancy to engineering plastics due to its catalytic charring effect and quenching effect in both the gaseous and condensed phase. ${ }^{30-33}$

Researchers often integrate the phosphonic acid group with other functional groups and exert phosphorus-rich residues in the condensed phase. ${ }^{34-38}$ This is widely used in engineering plastics such as polyamide6, polyamide66, polyethylene glycol terephthalate and polybutylene terephthalate, and has good flame-retardant effect because of its excellent thermal stability and high flame resistance. ${ }^{39-42}$ In our previous study, a type of alkyl-substituted phosphinate named 
aluminum poly-hexamethylenephosphinate (APHP) was successfully designed and synthesized. APHP also imposed flame retardant actions to epoxy thermosets in both the condensed phase and gaseous phase. Moreover, we further studied the synergistic flame retardancy of APHP/9,10dihydro-9-oxa-10-phosphaphenanthrene 10-oxide (DOPO) and APHP/bisphenol-A bis(diphenyl phosphate) (BDP). ${ }^{\mathbf{3 9 , 4 3 , 4 4}}$

In this study, a novel molecule containing phosphinate and triazine-trione was synthesized and named TAHP, and it was applied to an epoxy resin with another DOPO derivative, 1,3,5tris(3-(6-oxido-6H-dibenzo[c,e][1,2] oxaphosphinin-6-yl)propyl)1,3,5-triazinane-2,4,6-trione (TAD). ${ }^{11}$ The flame retardancy of the EP composites was evaluated and the synergistic flameretardant mechanism between TAHP and TAD in epoxy resin was also investigated.

\section{Experimental}

\subsection{Materials}

TAD (P-content: $10.33 \%$ ) was prepared in our laboratory. ${ }^{\mathbf{1 1}}$ The molecular structure of TAD is listed in Scheme 1. TAIC was provided by Yuyao Huihong Plastic Co. Ltd, China. Moreover, 2,2'-azobis(2-methylpropionamidine) dihydrochloride was supplied by HWRK Chem Co. Ltd, China. Hypophosphorous acid, aluminum chloride hexahydrate, 4,4'-diaminodiphenylmethane (DDM) and propanol were purchased from Sinopharm Chemical Reagent Co. Ltd China. Epoxy resin, diglycidyl ether of bisphenol-A (DGEBA), was purchased from Blue Star New Chemical Material Co. Ltd., China.

\subsection{Synthesis of TAHP}

Hypophosphorous acid (50 wt $\% \mathrm{H}_{2} \mathrm{O}$ ) (39.6 g, $0.3 \mathrm{~mol}$ ) was diluted in $19.8 \mathrm{~mL}$ of distilled water with mechanical stirring in a three-neck flask equipped with a reflux condenser. TAIC $(24.90 \mathrm{~g}, 0.1 \mathrm{~mol})$ dissolved in $60 \mathrm{~mL}$ of propanol was added into $\mathrm{s}$ flask using a constant pressure liquid funnel. Furthermore, 2,2'-azobis(2-methylpropionamidine) dihydrochloride

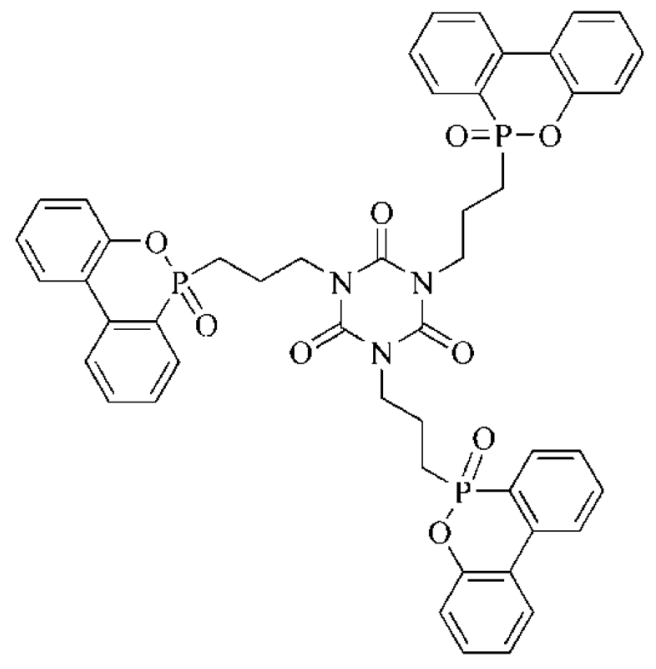

Scheme 1 The molecular structure of TAD.
$(0.41 \mathrm{~g}, 0.0015 \mathrm{~mol})$ was added into the reaction system as an initiator, repeating it every $2 \mathrm{~h}$ and for a total of three additions. The reaction temperature was $85{ }^{\circ} \mathrm{C}$ and the mixture was stirred for $24 \mathrm{~h}$. While the mixture became a white emulsion, aluminum chloride hexahydrate $(31.33 \mathrm{~g}, 0.13 \mathrm{~mol})$ dispersed in $100 \mathrm{~mL}$ of distilled water was added dropwise to the emulsion over $60 \mathrm{~min}$. After another $4 \mathrm{~h}$, more white granules appeared. Then, the granules were collected by filtration. The solids were washed with water at $80{ }^{\circ} \mathrm{C}$ and filtrated till the $\mathrm{pH}$ value of the solid was 7 . Finally, the product was dried at $120^{\circ} \mathrm{C}$. The reaction formula is shown in Scheme 2. The elemental contents of TAHP were C: $31.02 \mathrm{wt} \%, \mathrm{H}: 4.55 \mathrm{wt} \%$, N: $9.21 \mathrm{wt} \%$. The $n$ value representing the degree of polymerization in Scheme 2 was 0.13.

\subsection{Preparation of the epoxy thermosets}

DGEBA, TAHP and TAD were heated to $120{ }^{\circ} \mathrm{C}$ and stirred until TAHP and TAD were completely dispersed in DGEBA. DDM was then added to the mixture at $110{ }^{\circ} \mathrm{C}$ and blended thoroughly. After the mixture was degassed at $120^{\circ} \mathrm{C}$ for $3 \mathrm{~min}$, it was poured into the preheated molds and cured at $120^{\circ} \mathrm{C}$ for $2 \mathrm{~h}$ and then at $170{ }^{\circ} \mathrm{C}$ for $4 \mathrm{~h}$. The control sample DGEBA/DDM, which was named as EP, was also prepared in the same manner but without the addition of TAHP and TAD. Control samples with $4 \mathrm{wt} \%$ TAHP and $4 \mathrm{wt} \%$ TAD were also prepared and named as $4 \%$ TAHP/EP and $4 \% \mathrm{TAD} / \mathrm{EP}$, respectively. Table 1 provides the formulations of DGEBA, DDM, TAHP, and TAD in each epoxy resin thermoset.

\subsection{Characterization}

Fourier transform infrared (FTIR) spectra were obtained using a Nicolet iN10MX-type spectrometer. The powdered samples were thoroughly mixed with $\mathrm{KBr}$ and then pressed into pellets.

The elemental contents of TAHP were investigated via a Model 440 Elemental Analyzer. The tested specimens were $2 \mathrm{mg}$ and the results were an average of three repeated tests, and their error values were $\pm 0.3 \%$.

The ${ }^{1} \mathrm{H}$ nuclear magnetic resonance (NMR), ${ }^{13} \mathrm{C} \mathrm{NMR},{ }^{27} \mathrm{Al}$ NMR and ${ }^{31} \mathrm{P}$ NMR data were obtained using a Bruker $400 \mathrm{MHz}$ WB Solid-State NMR spectrometer. The resonance frequency of ${ }^{1} \mathrm{H}$ NMR, ${ }^{13} \mathrm{C}$ NMR, ${ }^{27} \mathrm{Al} \mathrm{NMR}$ and ${ }^{31} \mathrm{P}$ NMR was $400.25 \mathrm{MHz}$, 100.65 MHz, 104.29 MHz and 162.02 MHz, respectively. In the Solid Cross Polarization/Magic Angle Spinning test, the $7 \mathrm{~mm}$ rotor was used to detect ${ }^{31} \mathrm{P}$, and the $4 \mathrm{~mm}$ rotor was used to detect ${ }^{1} \mathrm{H},{ }^{13} \mathrm{C}$, and ${ }^{27} \mathrm{Al}$. At the sampling stage, spinal64 was used to decouple the sequence. The ${ }^{13} \mathrm{C}$ NMR data was referenced to the low field peak at $38.55 \mathrm{ppm}$ of adamantane.

Thermogravimetric analysis (TGA) was performed using a PerkinElmer instrument STA8000 thermal gravimetric analyzer. The sample was placed in a zirconia crucible and heated from $50{ }^{\circ} \mathrm{C}$ to $700{ }^{\circ} \mathrm{C}$ at a rate of $20{ }^{\circ} \mathrm{C} \mathrm{min}{ }^{-1}$ under $\mathrm{N}_{2}$ atmosphere. All tests were repeated twice and the typical TGA data were reproducible within $\pm 1 \%$.

The limited oxygen index (LOI) value was measured using a Fire Testing Technology (FTT, UK) Dynisco LOI instrument according to ASTM D2863-97 (sample dimension: $130.0 \mathrm{~mm} \times$ $6.5 \mathrm{~mm} \times 3.2 \mathrm{~mm}$ ). The LOI measurement for each specimen was repeated three times and their error values were $\pm 0.5 \%$. A 

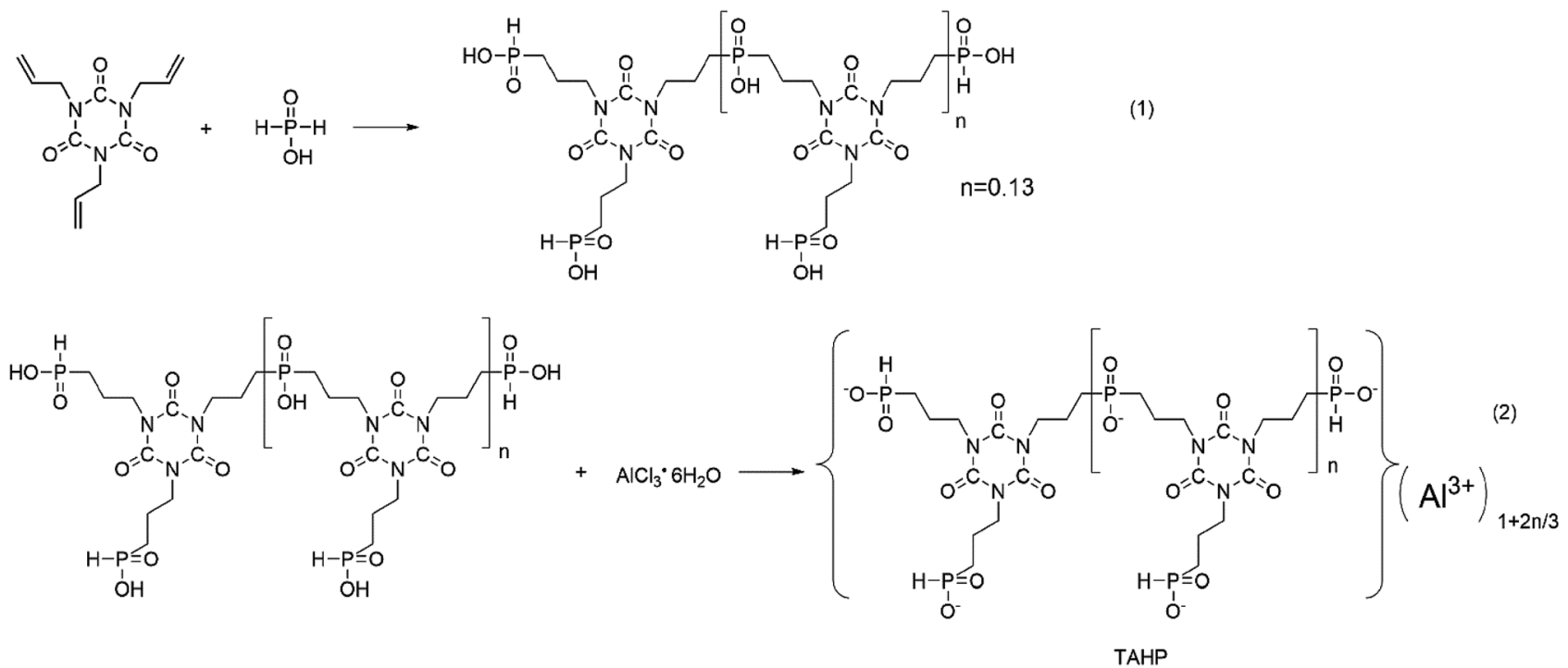

Scheme 2 The synthesis route used to prepare TAHP.

Table 1 The formulations of the epoxy thermosets

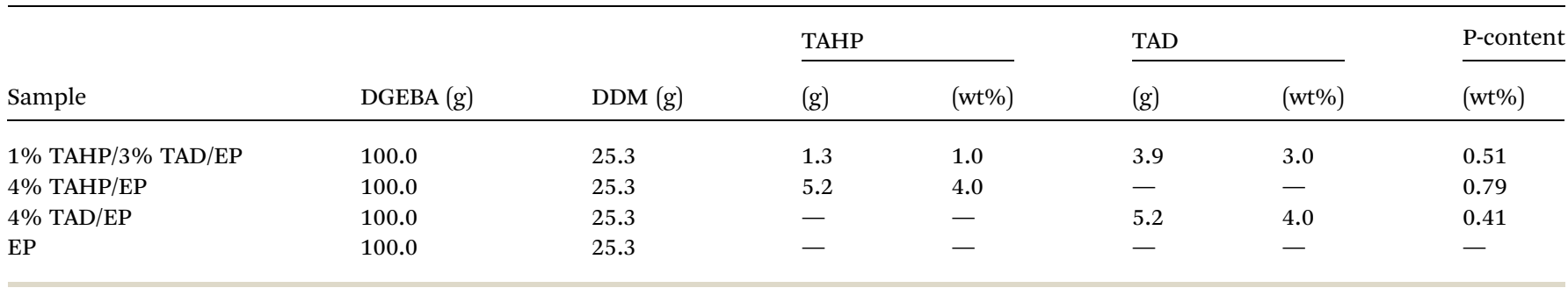

vertical burning test for the UL94 combustion level was performed using a FTT0082 instrument according to ASTM D3801 (sample dimension: $125.0 \mathrm{~mm} \times 12.7 \mathrm{~mm} \times 3.2 \mathrm{~mm}$ ).

Fire behavior was characterized using an FTT cone calorimeter based on ISO5660 at an external heat flux of $50 \mathrm{~kW} \mathrm{~m}^{-2}$. The sample dimension was $100.0 \mathrm{~mm} \times 100.0 \mathrm{~mm} \times 4.0 \mathrm{~mm}$. The reported parameters were the average from two measurements and their error values were $\pm 5 \%$.

The micromorphology images of the residues after the cone calorimeter tests were obtained using a Phenom Pro scanning electron microscopy (SEM) system under high vacuum conditions at a voltage of $10 \mathrm{kV}$.

The elemental contents of the residues obtained from the cone calorimeter test were investigated using a PerkinElmer PHI 5300 ESCA X-ray photoelectron spectrometer (XPS). The tested specimens were obtained from sufficiently mixed and ground residues, and the results were the average of two repeated tests and their error values were $\pm 10 \%$.

\section{Results and discussion}

\subsection{Characterization of the molecular structure of TAHP}

The chemical structure of TAHP was characterized using SolidState NMR spectrometer and FTIR. Fig. 1 presents the ${ }^{1} \mathrm{H}$ NMR, ${ }^{13} \mathrm{C}$ NMR, ${ }^{31} \mathrm{P}$ NMR and ${ }^{27} \mathrm{Al}$ NMR spectra of the TAHP sample. In Fig. 1(a), the ${ }^{1} \mathrm{H}$ NMR spectrum exhibited three absorptions at $1.61 \mathrm{ppm}, 3.34 \mathrm{ppm}$ and $5.38 \mathrm{ppm}$. The former two absorptions were attributed to the $\mathrm{C}-\mathrm{H}$ bonds of the methylene group in TAHP. Another peak at $5.38 \mathrm{ppm}$ was assigned to the $\mathrm{P}-\mathrm{H}$ bond of the target product. In Fig. 1(b), the absorption band at $149.58 \mathrm{ppm}$ in the ${ }^{13} \mathrm{C}$ NMR spectrum was assigned to the $\mathrm{C}=\mathrm{O}$ groups. The other three absorptions at $43.58 \mathrm{ppm}, 27.04 \mathrm{ppm}$ and $21.49 \mathrm{ppm}$ should belong to the tri-methylene groups. In Fig. 1(c), the ${ }^{31} \mathrm{P}$ NMR spectrum showed two absorption bands at $35.86 \mathrm{ppm}$ and $18.95 \mathrm{ppm}$, which were caused by the $\mathrm{P}$ atoms in the $\mathrm{C}-\mathrm{P}-\mathrm{C}$ and $\mathrm{C}-\mathrm{P}-\mathrm{H}$ structures, respectively. In Fig. 1(d), the single strong peak at $-14.72 \mathrm{ppm}$ was attributed to aluminum absorption in aluminum alkyl-phosphinate, which corresponds to the chemical structure of the target molecule. ${ }^{33}$ In addition, the single aluminum absorption also confirmed that all the aluminum atoms stayed in the same chemical environment, which proved that no inorganic aluminum hypophosphite existed in the products.

As shown in Fig. 2, the obtained peaks in the TAIC FTIR spectrum $\left(\mathrm{KBr}, \mathrm{cm}^{-1}\right)$ were $3085 \mathrm{~cm}^{-1}(\mathrm{C}=\mathrm{C}), 1690 \mathrm{~cm}^{-1}(\mathrm{C}=$ $\mathrm{O})$, and $1455 \mathrm{~cm}^{-1}(\mathrm{C}-\mathrm{N})$; the obtained peaks in the TAHP FTIR spectrum $\left(\mathrm{KBr}, \mathrm{cm}^{-1}\right)$ had no absorption for the $\mathrm{C}=\mathrm{C}$ bonds around $3085 \mathrm{~cm}^{-1}$ and exhibited the absorption of $1680 \mathrm{~cm}^{-1}$ $(\mathrm{C}=\mathrm{O})$ and $1461 \mathrm{~cm}^{-1}(\mathrm{C}-\mathrm{N})$ from the triazine-trione group, showing the absorption peaks at $2365 \mathrm{~cm}^{-1}(\mathrm{P}-\mathrm{H}), 1164 \mathrm{~cm}^{-1}$ $(\mathrm{P}=\mathrm{O})$, and $1085 \mathrm{~cm}^{-1}(\mathrm{P}-\mathrm{O})$ from the hypophosphite group. All the results indicate the occurrence of the addition reaction 


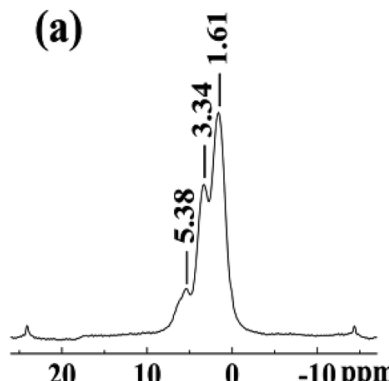

(b)

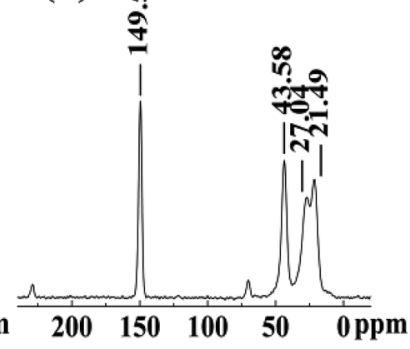

(c)

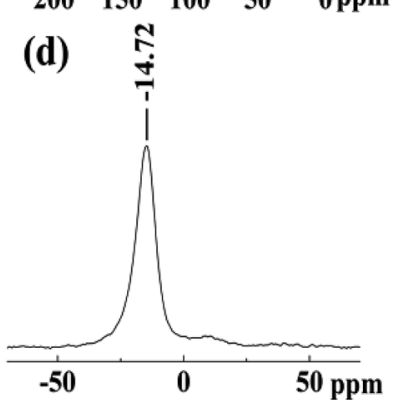

Fig. 1 The (a) ${ }^{1} \mathrm{H} N M R$, (b) ${ }^{13} \mathrm{C}$ NMR, (c) ${ }^{31} \mathrm{P} N M R$ and (d) ${ }^{27} \mathrm{Al} N M R$ spectra of TAHP.

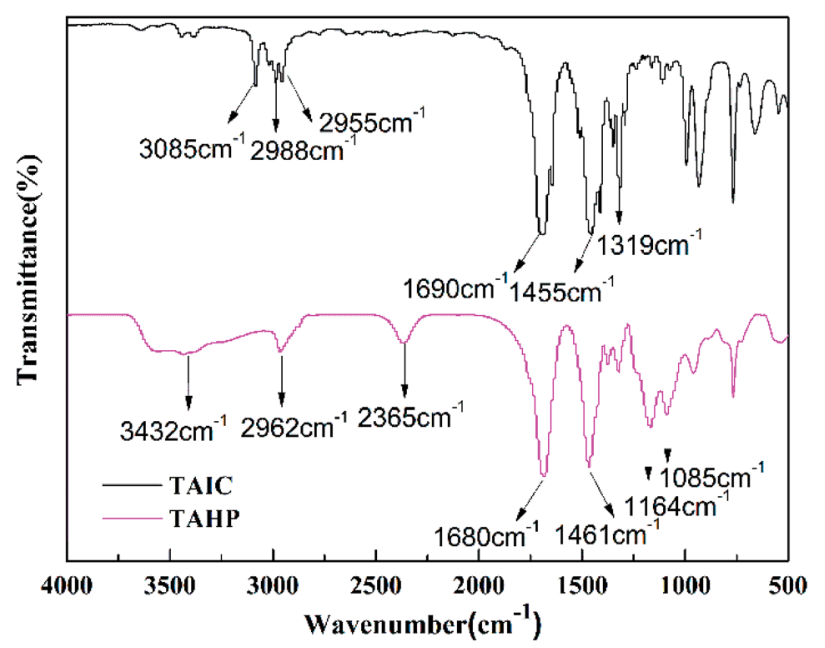

Fig. 2 The FTIR spectra of TAHP.

between TAIC and hypophosphorous acid. The SSNMR and FTIR characterizations demonstrate that the TAHP was successfully synthesized.

\subsection{TGA analysis}

The TGA curves of TAHP and epoxy thermosets are shown in Fig. 3, and some of the typical data are listed in Table 2. The thermal stability behavior of TAHP and the epoxy thermosets under nitrogen atmosphere is shown in Fig. 3(a). The onset degradation temperature $\left(T_{\mathrm{d}, 5 \%}\right)$ of TAHP was $419{ }^{\circ} \mathrm{C}$, implying that TAHP possessed a higher thermal stability than the epoxy thermosets. The residue weight of TAHP at $600{ }^{\circ} \mathrm{C}$ was about $51.2 \mathrm{wt} \%$ and most of the TAHP contents were reserved in the residue, which implies that its flame-retardant effect possibly
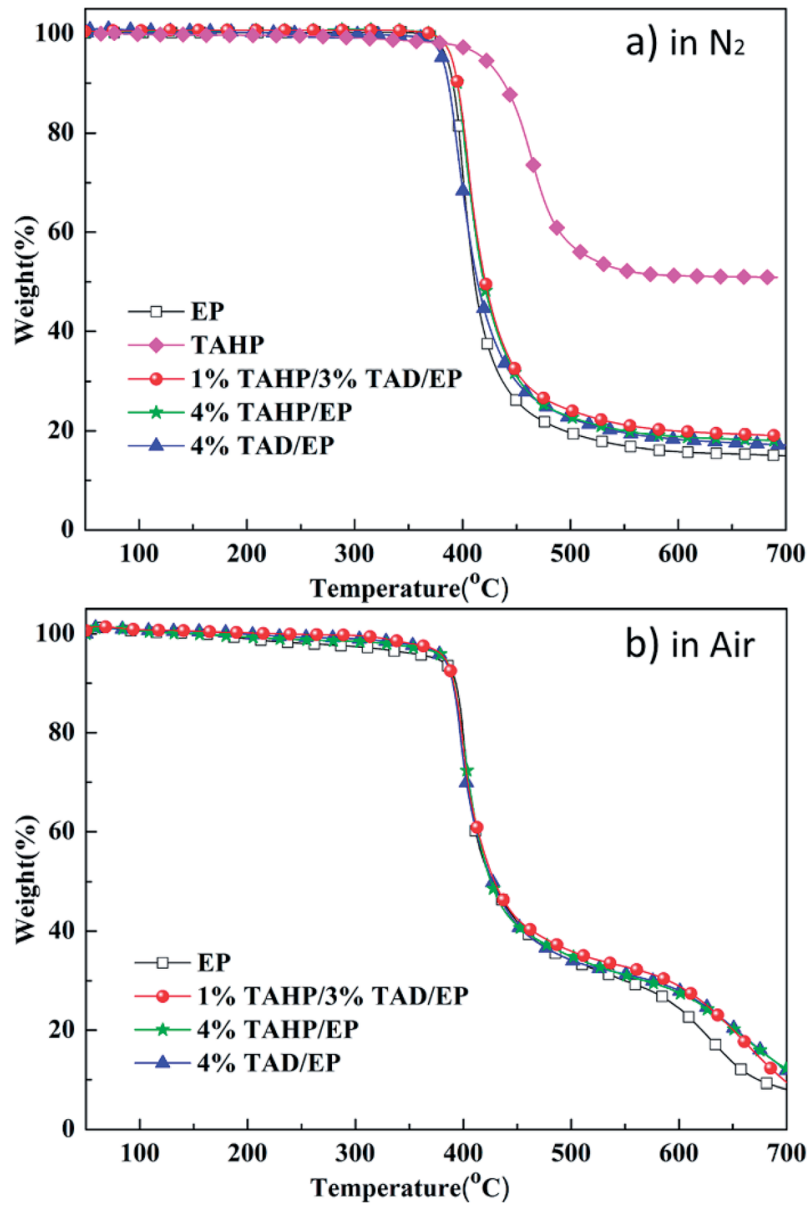

Fig. 3 TGA curves of the TAHP and epoxy thermosets (a) in $N_{2}$ atmosphere, (b) in air atmosphere.

worked more in the condensed phase. In the TAHP/TAD/EP sample, the onset degradation temperature $\left(T_{\mathrm{d}, 5 \%}\right)$ and the temperature of maximum decomposition rate $\left(T_{\max }\right)$ are similar as those of $4 \% \mathrm{TAHP} / \mathrm{EP}, 4 \% \mathrm{TAD} / \mathrm{EP}$ and $\mathrm{EP}$, indicating that TAHP did not exert its flame retardancy through inducing the decomposition of the thermosets. The residual weight at $600{ }^{\circ} \mathrm{C}$ of $1 \% \mathrm{TAHP} / 3 \% \mathrm{TAD} / \mathrm{EP}$ was also slightly higher than those of 4\% TAHP/EP, 4\% TAD/EP and EP. Although the char yields increased very slightly, it still possibly disclosed that TAD and TAHP had a synergistic action on locking the composition of the thermosets in the residues or promotion of charring during thermal decomposition.

In contrast to the one-step decomposition process in $\mathrm{N}_{2}$, the thermal decomposition behavior in an air atmosphere of the epoxy thermosets showed a two-step process and the curves are displayed in Fig. 3(b). All the flame retardant samples have similar degradation behavior and their residue yields are higher than pure EP, implying that the TAHP/TAD system did not decrease the thermal stability and promoted charring of the epoxy resin matrix in an air atmosphere. Therefore, the TAHP/TAD system reserved the higher stability of the epoxy matrix and also promoted charring both in a $\mathrm{N}_{2}$ and air atmosphere. 
Table 2 The thermal parameters of the epoxy thermosets ${ }^{a}$

\begin{tabular}{|c|c|c|c|c|c|c|}
\hline \multirow[b]{2}{*}{ Sample } & \multicolumn{3}{|l|}{$\mathrm{N}_{2}$} & \multicolumn{3}{|l|}{ Air } \\
\hline & $T_{\mathrm{d}, 5 \%}\left({ }^{\circ} \mathrm{C}\right)$ & $T_{\max }\left({ }^{\circ} \mathrm{C}\right)$ & $R_{600}{ }^{\circ} \mathrm{C}(\%)$ & $T_{\mathrm{d}, 5 \%}\left({ }^{\circ} \mathrm{C}\right)$ & $T_{\max }\left({ }^{\circ} \mathrm{C}\right)$ & $\begin{array}{l}R_{600}{ }^{\circ} \mathrm{C} \\
(\%)\end{array}$ \\
\hline 1\% TAHP/3\% TAD/EP & 390 & 405 & 19.9 & 383 & 398 & 28.9 \\
\hline $4 \%$ ТАНР/ЕР & 390 & 401 & 18.8 & 383 & 401 & 27.6 \\
\hline $4 \% \mathrm{TAD} / \mathrm{EP}$ & 381 & 395 & 18.2 & 381 & 397 & 27.9 \\
\hline
\end{tabular}

\subsection{The flame-retardant behavior of the epoxy thermosets}

3.3.1. LOI and UL94 vertical tests. After the structure of TAHP was confirmed, TAHP was incorporated into the epoxy thermosets to research its flame-retardant effect. The flameretardant properties of the epoxy thermosets were detected first using LOI and UL94 vertical burning tests and the test results are listed in Table 3. In the control samples, the pure EP sample only achieved a LOI value of $26.2 \%$ and had no rating in the UL94 test. The LOI value of the epoxy thermoset was significantly increased to $34.5 \%$ after TAHP was added but the UL94 test results remained with no rating although more residue was observed after the LOI and UL94 tests. The results indicate that TAHP had a significant flame-retardant effect but the effect may not appropriately work in the gaseous and condensed phases, resulting in the worse performance in the UL94 tests. According to the burning phenomenon of the thermosets with TAHP alone, TAHP should exert its action more in the condensed phase. Therefore, for improving the flame retardancy of the system in the gaseous phase, it is assumed that the incorporation of TAD with excellent flame retardancy in the gaseous phase can make the flame retardancy disperse evenly both in the condensed and gaseous phases. Although $4 \%$ TAHP/EP and $4 \%$ TAD/EP both failed to pass the V-0 rating in the UL94 test, 1\% TAHP/3\% TAD/EP acquired an LOI value of $36.0 \%$ and passed the UL94 V-0 rating. Compared with the LOI and UL94 values of the thermosets containing $4 \mathrm{wt} \%$ TAHP or $4 \mathrm{wt} \%$ TAD alone, the higher LOI value and the higher UL94 rating of $1 \% \mathrm{TAHP} / 3 \% \mathrm{TAD} / \mathrm{EP}$ indicate the existence of the flame-retardant synergistic effect between TAHP and TAD. The synergy was caused by optimizing the distribution of the flameretardant effect of the condensed phase and gaseous phase. According to the results, our preliminarily assumption of the flame retardant system was also confirmed.

Table 3 The LOI and UL94 test results of the epoxy thermosets

\begin{tabular}{|c|c|c|c|c|c|}
\hline \multirow[b]{2}{*}{ Sample } & \multirow[b]{2}{*}{ LOI (\%) } & \multicolumn{4}{|l|}{ UL94 } \\
\hline & & av- $t_{1}$ & av- $t_{2}$ & Rating & Dripping \\
\hline $1 \% \mathrm{TAHP} / 3 \% \mathrm{TAD} / \mathrm{EP}$ & 36.0 & 2.6 & 1.9 & $\mathrm{~V}-0$ & No \\
\hline $4 \%$ TAHP/EP & 34.5 & 30.5 & 35.4 & Unrated & No \\
\hline $4 \% \mathrm{TAD} / \mathrm{EP}$ & 33.6 & 10.3 & 4.3 & $\mathrm{~V}-1$ & No \\
\hline EP & 26.2 & Infinite & - & Unrated & Yes \\
\hline
\end{tabular}

3.3.2. Cone calorimeter test. A cone calorimeter test is usually conducted to investigate the combustion behavior of polymer materials. The curves obtained for the heat release rate (HRR), normalized mass loss and total smoke release (TSR) are shown in Fig. 4, 5 and 6, respectively. Table 4 summarizes the partial characteristic parameters, such as time to ignition (TTI), peak of heat release rate (pk-HRR), total heat release (THR), total mass loss (TML), average of effective heat of combustion (av-EHC), total smoke release (TSR), average CO yield (av-COY) and average $\mathrm{CO}_{2}$ yield $\left(\operatorname{av}-\mathrm{CO}_{2} \mathrm{Y}\right)$.

As shown in Table 4 , the TTI value of $1 \%$ TAHP/3\% TAD/EP was lower than that of pure EP, which is consistent with that of the control sample $4 \% \mathrm{TAD} / \mathrm{EP}$ and has an obvious difference with that of $4 \%$ TAHP/EP. Furthermore, $4 \%$ TAHP/EP has a similar TTI value as that of pure EP. The TTI value imply that $1 \%$ TAHP/3\% TAD system obtained the inducing early decomposition effects from TAD, which TAHP is lack of due to its high thermal stability. However, the different effects on the thermal decomposition of the thermosets from TAD and TAHP possibly balanced the flame retardancy in the gaseous phase and condensed phase, contributing to enhancing the flameretardant performance.

In Fig. 4 and Table 4 , the TAHP/TAD system exhibited a better effect on inhibiting the burning intensity. TAHP alone in the epoxy thermoset promoted more residue reserved and reduced peak value of $\mathrm{HRR}$ but it was less effective on decreasing the THR and av-EHC values compared with TAD

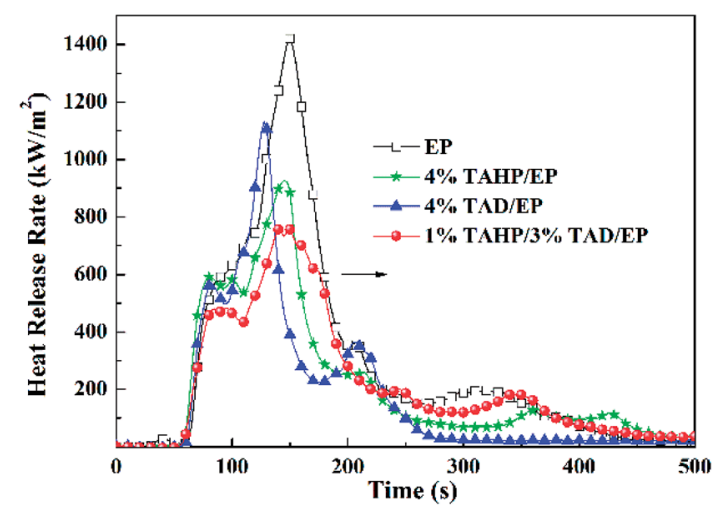

Fig. 4 HRR curves of the epoxy thermosets. 


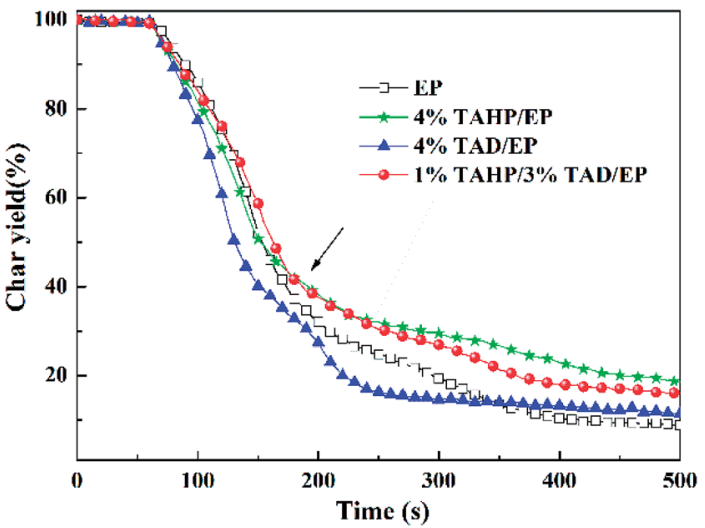

Fig. 5 The normalized mass loss curves of the epoxy thermosets from the cone calorimeter test.

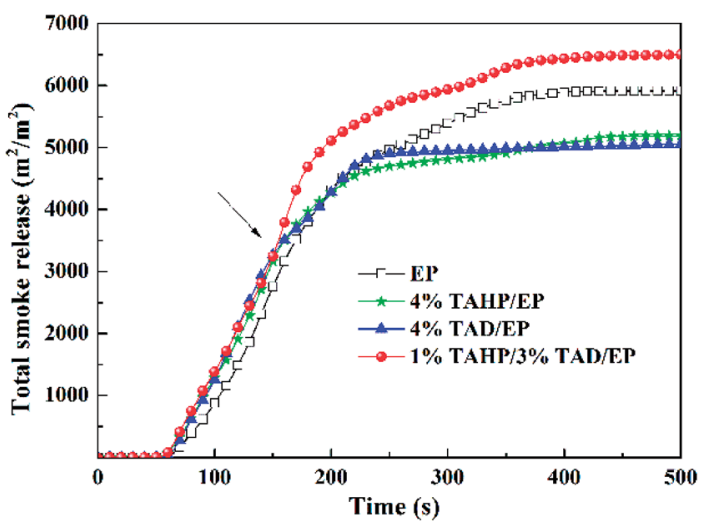

Fig. 6 TSR curves of the epoxy thermosets from the cone calorimeter test.

alone in the epoxy thermoset, which implies that TAHP had more actions in the charring effect to form a barrier effect on fire in the condensed phase. Compared with TAHP, TAD endowed the epoxy thermoset with lower THR and av-EHC values, which were caused by the quenching effect of the decomposed TAD fragments in the gaseous phase. Their mixture, $1 \mathrm{wt} \% \mathrm{TAHP} / 3 \mathrm{wt} \% \mathrm{TAD}$, brought about the lower peak value of HRR and a higher value of THR to the epoxy thermoset, indicating that the two flame retardants possessed an apparent synergistic effect in inhibiting the burning intensity but did not show an effect to reduce the THR value.

Fig. 5 shows the mass loss curves and the TML data listed in Table 4. In Fig. 5, with increasing temperature, the mass of $4 \%$
TAD/EP decreased rapidly, implying that TAD promoted thermal decomposition of the matrix; differently, $4 \%$ TAHP/EP reserved about $20 \mathrm{wt} \%$ residue, which surpasses $10 \mathrm{wt} \%$ in contrast to pure EP and was also more than $4 \% \mathrm{TAD} / \mathrm{EP}$. The results further verify that TAHP mainly worked in the condensed phase. The mass loss ratio of $1 \%$ TAHP/3\% TAD/EP was always less than those of $4 \% \mathrm{TAHP} / \mathrm{EP}$ and $4 \% \mathrm{TAD} / \mathrm{EP}$ before $180 \mathrm{~s}$, implying that $1 \% \mathrm{TAHP} / 3 \% \mathrm{TAD}$ has an interaction on decreasing the mass loss and that the formation of more residue effectively reduces the fuel release and forms a barrier effect on hindering combustion. Therefore, $1 \%$ TAHP/3\% TAD can impose a lower peak value of the HRR to the epoxy thermoset.

The curves of total smoke release shown in Fig. 6 also disclosed the interaction between TAHP and TAD. During combustion, $1 \% \mathrm{TAHP} / 3 \% \mathrm{TAD}$ after $150 \mathrm{~s}$ caused obviously more smoke release than the thermosets with TAHP or TAD alone, implying that TAHP and TAD jointly interacted to generate more char fragments instead of fuels. Some char fragments were locked in the residues and some of them were released to the gaseous phase to form dense smoke. Therefore, it is also an evidence of the interaction between TAHP and TAD. In addition, the av-COY and av- $\mathrm{CO}_{2} \mathrm{Y}$ value of $1 \% \mathrm{TAHP} / 3 \% \mathrm{TAD} / \mathrm{EP}$ remained between $4 \% \mathrm{TAHP} / \mathrm{EP}$ and $4 \% \mathrm{TAD} / \mathrm{EP}$, which is consistent with the avEHC value, indicating that the TAHP/TAD system reserved the ability to promote incomplete combustion.

Eqn (1)-(3) were used to calculate values of three different main flame-retardant effects, ${ }^{33,40}$ and Table 5 lists the calculation results. According to Table 5, TAHP possessed three flameretardant effects simultaneously, whereas TAD had a negative effect on the barrier effect but possessed a better flame inhibition effect. When TAHP and TAD were jointly used in the thermosets, $1 \% \mathrm{TAHP} / 3 \% \mathrm{TAD} / \mathrm{EP}$ generated an outstandingly higher barrier effect, and its flame inhibition effect was reduced obviously compared with the theoretical value obtained from the addition calculation of $(1 / 4) \times 4 \%$ TAHP/EP and $(3 / 4) \times 4 \%$ $\mathrm{TAD} / \mathrm{EP}$. The results imply that the $1 \% \mathrm{TAHP} / 3 \% \mathrm{TAD}$ system optimized the distribution of the flame-retardant effects in the condensed and gaseous phases.

$$
\begin{gathered}
\text { Flame inhibition effect }=1-\mathrm{EHC}_{\mathrm{FREP}} / \mathrm{EHC}_{\mathrm{EP}} \\
\text { Charring effect }=1-\mathrm{TML}_{\mathrm{FREP}} / \mathrm{TML}_{\mathrm{EP}}
\end{gathered}
$$

Barrier effect $=1-\left(\mathrm{pk}-\mathrm{HRR}_{\mathrm{FREP}} / \mathrm{pk}-\mathrm{HRR}_{\mathrm{EP}}\right) /$

$$
\left(\mathrm{THR}_{\mathrm{FREP}} / \mathrm{THR}_{\mathrm{EP}}\right)
$$

FREP $=$ flame retardant epoxy resin.

Table 4 The typical parameters obtained from the cone calorimeter test of the epoxy thermosets

\begin{tabular}{llllllll}
\hline Sample & TTI $(\mathrm{s})$ & $\begin{array}{l}\text { pk-HRR } \\
\left.(\mathrm{kW} \mathrm{m})^{-2}\right)\end{array}$ & $\begin{array}{l}\text { THR } \\
\left.(\mathrm{MJ} \mathrm{m})^{-2}\right)\end{array}$ & TML $(\mathrm{wt} \%)$ & $\begin{array}{l}\text { av-EHC } \\
\left(\mathrm{MJ} \mathrm{kg}^{-1}\right)\end{array}$ & $\begin{array}{l}\text { TSR } \\
\left(\mathrm{m}^{2} \mathrm{~m}^{-2}\right)\end{array}$ & $\begin{array}{l}\text { av-COY } \\
\left(\mathrm{kg} \mathrm{kg}^{-1}\right)\end{array}$ \\
\hline 1\% TAHP/3\% TAD/EP & 44 & 757 & 111 & 85.8 & 24.7 & 6514 & 0.134 \\
$4 \%$ TAHP/EP & 54 & 927 & 108 & 83.4 & 26.6 & 5188 & 0.123 \\
$4 \%$ TAD/EP & 46 & 1106 & 89 & 89.5 & 21.2 & 5085 & 0.136 \\
EP & 56 & 1420 & 144 & 91.5 & 29.9 & 5906 & 0.126
\end{tabular}


Table 5 The quantitative evaluation of three flame-retardant effects

\begin{tabular}{llll}
\hline Sample & $\begin{array}{l}\text { Flame inhibition } \\
\text { effect }\end{array}$ & Charring effect & $\begin{array}{l}\text { Barrier } \\
\text { effect }\end{array}$ \\
\hline $1 \% \mathrm{TAHP} / 3 \% \mathrm{TAD} / \mathrm{EP}$ & $17.4 \%$ & $6.2 \%$ & $30.8 \%$ \\
$1 \% \mathrm{TAHP} / 3 \% \mathrm{TAD} / \mathrm{EP}^{a}$ & $24.5 \%$ & $3.9 \%$ & $-16.3 \%$ \\
$4 \% \mathrm{TAHP} / \mathrm{EP}$ & $11.0 \%$ & $8.9 \%$ & $12.9 \%$ \\
$4 \% \mathrm{TAD} / \mathrm{EP}$ & $29.1 \%$ & $2.2 \%$ & $-26 \%$
\end{tabular}

${ }^{a}$ Theoretical calculating value.

3.4. Morphology, FTIR spectra and element compositions of the residues obtained from the cone calorimeter test

3.4.1. The macroscopic and microscopic morphologies of residues. Fig. 7(a)-(c) show the macroscopic digital photographs of the residual char layers and (d), (e) and (f) show the SEM images of the epoxy thermoset residues obtained from the cone calorimeter test. As shown in Fig. 7(a), the 4\% TAHP/EP sample formed a dense residue layer, which indicates that TAHP promoted the formation of more residue, corresponding with the results obtained from the cone calorimeter test. After TAD was incorporated into the epoxy thermoset (Fig. 7(b)), the status of the char, particularly the middle part, was fluffy and loose, which was caused by the increased gas release under the actions of TAD. ${ }^{11}$ In Fig. 7(c), the residual char of 1\% TAHP/3\% TAD/EP exhibited a more complete morphology, demonstrating that TAHP and TAD jointly generated a char layer with a better barrier effect. Therefore, the char layer efficiently weakened the heat transmission of the inner matrix and reduced the intensity of the matrix decomposition, which was consistent with the results obtained for the HRR value in Fig. 4.

The microscopic morphologies of the residues were further characterized via SEM. In Fig. 7(d), open holes formed on the char surface of $4 \% \mathrm{TAHP} / \mathrm{EP}$, and numerous small particles appeared on the char layer surface, which was determined as aluminum phosphate from the decomposed TAHP pieces. ${ }^{33}$ In Fig. 7(e), there were a few open holes on the char surface of $4 \%$ TAD/EP and most of the char layer exhibited a smooth and
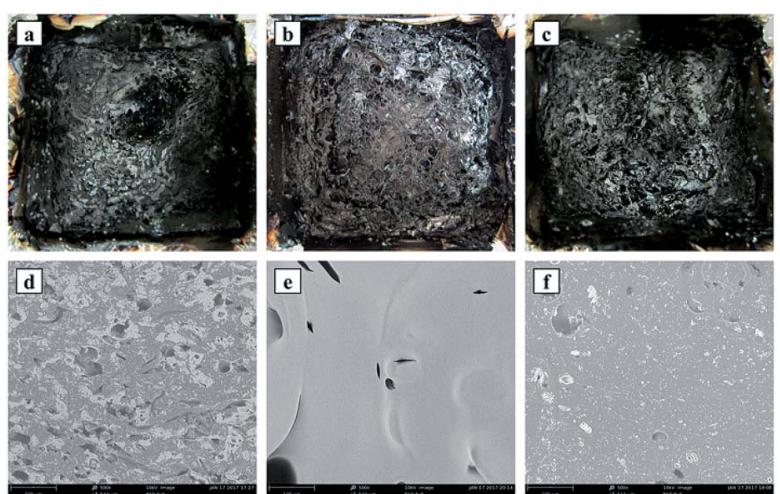

Fig. 7 The digital and SEM photographs of the char residues. Digital: (a) 4\% TAHP/EP, (b) 4\% TAD/EP and (c) 1\% TAHP/3\% TAD/EP; SEM: (d) $4 \% \mathrm{TAHP} / \mathrm{EP} \times 500$, (e) $4 \% \mathrm{TAD} / \mathrm{EP} \times 500$ and (f) $1 \% \mathrm{TAHP} / 3 \% \mathrm{TAD} / \mathrm{EP}$ $\times 500$. complete status. Fig. 7(f) displays few closed holes and a lot of solid products from the decomposed TAHP on the char layer surface of $1 \%$ TAHP/3\% TAD/EP and the open holes in $4 \%$ TAHP/EP and 4\% TAD/EP were not obvious. The results reveal that $1 \mathrm{wt} \% \mathrm{TAHP} / 3 \mathrm{wt} \%$ TAD exerted an interaction in the condensed phase and led to the formation of a well-sealed char layer, which effectively inhibited the exchange of fuel and oxygen and protected the matrix from fire, which is why the barrier effect of the TAHP/TAD system was significantly enhanced.

3.4.2. Elemental analysis of the residues after the cone calorimeter test. To further explore synergistic barrier effect, XPS was used to detect the elemental content of the residues on the char surface obtained from the cone calorimeter test, and Table 6 displays the obtained results. The phosphorus (P) content of the $1 \%$ TAHP/3\% TAD/EP residue was outstandingly higher than those of residues only containing TAHP or TAD. Furthermore, the ratios between the remaining $\mathrm{P}$ mass in the residue and the initial $\mathrm{P}$ mass in sample $\left(R_{\mathrm{rP} / \mathrm{iP}}\right)$ of $1 \% \mathrm{TAHP} / 3 \%$ $\mathrm{TAD} / \mathrm{EP}, 4 \% \mathrm{TAHP} / \mathrm{EP}$, and $4 \% \mathrm{TAD} / \mathrm{EP}$ were calculated using the equation: $R_{\mathrm{rP} / \mathrm{iP}}=$ (residue ratio $\times \mathrm{P}$ ratio in char residue) $/$ (initial $\mathrm{P}$ ratio in epoxy thermosets); the resulting values were $58.26 \%, 29.32 \%$, and $19.28 \%$, respectively, which imply that $1 \%$ $\mathrm{TAHP} / 3 \% \mathrm{TAD} / \mathrm{EP}$ reserved more $\mathrm{P}$ content in the residues. As previously discussed, this should be caused due to the Pcontaining fragments obtained from the pyrolysis of TAD interacting with the decomposed TAHP; thus, more of them were locked in the residues. The formation of P-rich residues from the interaction of TAHP and TAD during combustion possessed a strong barrier effect, which could weaken the combustion intensity. The ratios between the remaining $\mathrm{N}$ mass in the samples of $1 \% \mathrm{TAHP} / 3 \% \mathrm{TAD} / \mathrm{EP}, 4 \% \mathrm{TAHP} / \mathrm{EP}$, and $4 \%$ $\mathrm{TAD} / \mathrm{EP}$ and the remaining $\mathrm{N}$ mass in the sample of EP were calculated using the equation $\left(R_{\mathrm{rN} / \mathrm{rN}}\right)=$ ( $\mathrm{N}$ ratio in residue of the flame retardant sample)/( $\mathrm{N}$ ratio in residue of EP sample); the resulting values were $1.46,1.36$, and 0.65 , respectively, which imply that the addition of TAHP increased the $\mathrm{N}$ elements in the residues. After incorporation of TAHP/TAD jointly into EP matrix, the reserved $\mathrm{P}$ and $\mathrm{N}$ contents in the residue all increased, indicating that more flame retardant contents were formed in the residue to strengthen the condensed-phase flame retardant effect.

3.4.3. The FTIR spectra of the residues after the cone calorimeter test. As discussed in the elemental analysis of the residues, there was a P-rich char layer in the $1 \%$ TAHP/3\% TAD/ EP sample. Therefore, what is reserved in the condensed phase

Table 6 The elemental contents of the residues obtained from the cone calorimeter test by XPS

Element content (wt\%)

\begin{tabular}{lllll} 
Sample & $\mathrm{C}$ & $\mathrm{N}$ & $\mathrm{O}$ & $\mathrm{P}$ \\
\hline 1\% TAHP/3\% TAD/EP & 78.19 & 6.33 & 13.82 & 1.66 \\
$4 \%$ TAHP/EP & 81.93 & 5.89 & 11.05 & 1.13 \\
$4 \%$ TAD/EP & 85.70 & 2.81 & 10.97 & 0.52
\end{tabular}


to form the P-rich residue? As shown in Fig. 8, the FTIR spectra of the different residues show the absorption peaks with some differences. These differences can provide some answers to the question.

In the spectrum of $1 \% \mathrm{TAHP} / 3 \% \mathrm{TAD} / \mathrm{EP}$, the main differences appeared in the bands near $1118 \mathrm{~cm}^{-1}, 934 \mathrm{~cm}^{-1}$ and $715 \mathrm{~cm}^{-1}$. The former two bands have an obvious intensity change and the later one is the new band, which was not observed in the spectra of the $4 \%$ TAHP/EP and $4 \%$ TAD/EP residues. The band at $1118 \mathrm{~cm}^{-1}$ corresponds to $\mathrm{P}=\mathrm{O}$, and the band at $934 \mathrm{~cm}^{-1}$ corresponds to the $\mathrm{P}-\mathrm{O}-\mathrm{C}$. The band at $715 \mathrm{~cm}^{-1}$ only appeared in the residues of $1 \% \mathrm{TAHP} / 3 \% \mathrm{TAD} /$ $\mathrm{EP}$, corresponding to the aromatic groups. The remarkably higher $\mathrm{P}$ and oxygen contents in the elemental analysis test (Table 6) and the stronger intensity of $\mathrm{P}=\mathrm{O}$ and $\mathrm{P}-\mathrm{O}-\mathrm{R}$ indicates that the char surface of $1 \%$ TAHP/3\% TAD/EP obviously should be composed of phosphorus oxides or phosphate and carbonaceous compounds. ${ }^{33}$ The results further verified that TAHP and TAD generated interactions during combustion to lock more contents containing phosphorus in the condensed phase. This is direct interaction evidence of TAHP and TAD in the condensed phase, thereby strengthening the barrier effect on fire.

\subsection{Flame-retardant mechanism: the synergistic barrier effect between TAHP and TAD in the epoxy thermosets}

According to all the above discussions, the flame-retardant mechanism of TAHP/TAD in the epoxy thermosets was concluded as follows and is illustrated in Fig. 9. After the thermosets were ignited, both TAHP and TAD decomposed into triazine-trione pieces and P-containing fragments. Due to the interaction of TAHP and TAD, most of the P-containing fragments were locked in the residues to form a char layer with a better barrier effect, which is composed of the P-containing contents and aluminum phosphate. Although the flame inhibition effect of TAHP/TAD was weakened because of the reduced release of the P-containing fragments, their synergistic barrier effect was outstandingly strengthened. The flame-

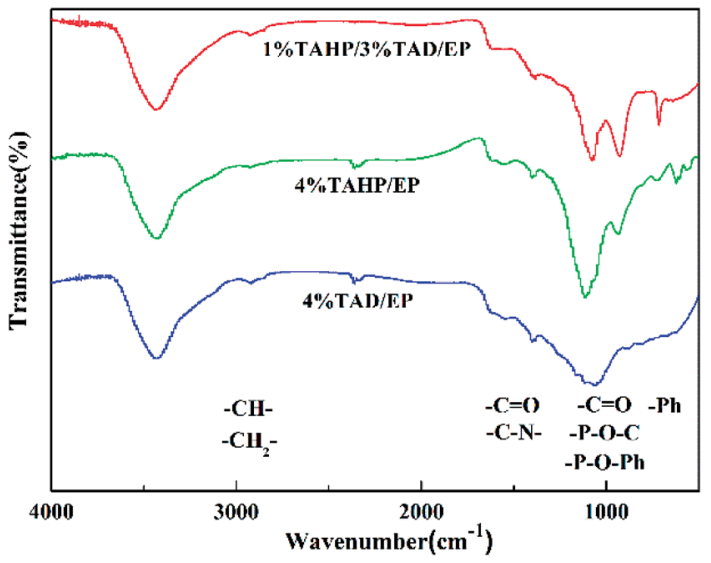

Fig. 8 The FTIR spectra of the char residue obtained from the cone calorimeter test.

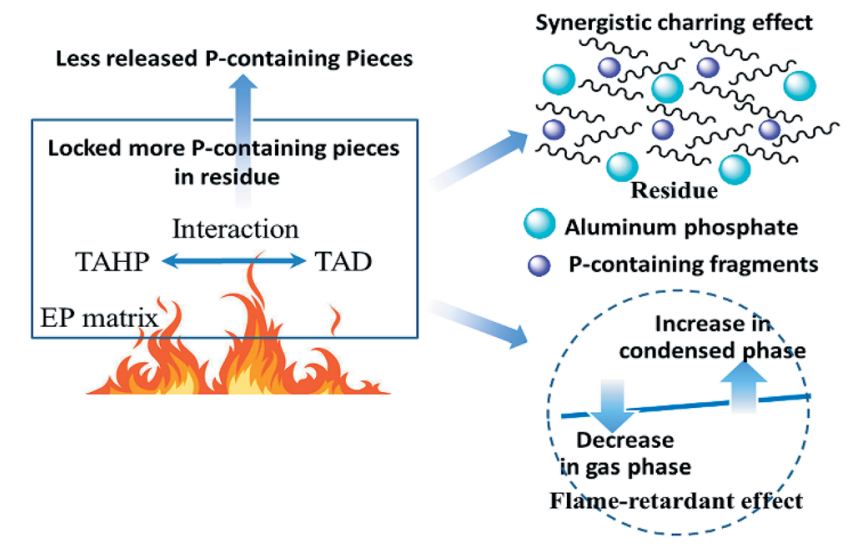

Fig. 9 The synergistic flame-retardant mechanism of TAHP/TAD in the epoxy thermoset.

retardant actions in the gaseous phase and condensed phase were redistributed and balanced, thereby imposing better flame-retardant performance to the epoxy thermosets.

\section{Conclusions}

A novel flame-retardant TAHP constructed by phosphinate and triazine-trione groups was synthesized and characterized. Then, TAHP and TAD were incorporated into the epoxy thermosets to explore the flame-retardant effect. Comparing with the thermosets with TAHP or TAD alone at the same mass fraction, the TAHP/TAD system can impose a higher LOI value and UL94 rating, and lower pk-HRR value. During combustion, the TAHP/ TAD system jointly worked on reserving more P-containing fragments to form a phosphorus-rich char layer mixed with aluminum phosphate. The results confirm the synergistic charring effect of the TAHP/TAD system in the condensed phase causing more balanced flame-retardant actions in the gaseous phase and condensed phase. This is the main reason that TAHP/ TAD can impose better flame retardancy to epoxy thermosets.

\section{Conflicts of interest}

There are no conflicts to declare.

\section{Acknowledgements}

Financial support was provided by the National Natural Science Foundation of China (No. 21374003) and the Key Project of the Science and Technology Plan of Beijing Municipal Education Commission \& Beijing Natural Science Foundation (No. KZ201510011009).

\section{References}

1 X. E. Xiao, S. R. Lu, B. Qi, C. Zeng, Z. K. Yuan and J. H. Yu, RSC Adv., 2014, 4, 14928-14935.

2 N. Tian, R. C. Ning and J. Kong, Polymer, 2016, 99, 376-385. 
3 D. H. Tang, J. Q. Su, Q. Yang, M. Q. Kong, Z. G. Zhao, Y. J. Huang, X. Liao and Y. Liu, RSC Adv., 2015, 5, 5517055178.

4 S. Q. Ma and D. C. Webster, Macromolecules, 2015, 48, 71277137.

5 Y. Qiu, L. J. Qian and W. Xi, RSC Adv., 2016, 6, 56018-56027. 6 B. W. Liu, H. B. Zhao, Y. Tan, L. Chen and Y. Z. Wang, Polym. Degrad. Stab., 2015, 122, 66-76.

7 M. Raimondo, S. Russo, L. Guadagno, P. Longo, S. Chirico, A. Mariconda, L. Bonnaud, O. Murariu and P. Dubois, RSC Adv., 2015, 5, 10974-10986.

8 S. Wang, S. Q. Ma, C. X. Xu, Y. Liu, J. Y. Dai, Z. B. Wang, X. Q. Liu, J. Chen, X. B. Shen, J. J. Wei and J. Zhu, Macromolecules, 2017, 50, 1892-1901.

9 W. K. P. Lim, M. Mariatti, W. S. Chow and K. T. Mar, Composites, Part B, 2012, 43, 124-128.

10 S. Tang, L. J. Qian, Y. Qiu and N. Sun, J. Appl. Polym. Sci., 2014, 131, 40558.

11 S. Tang, V. Wachtendorf, P. Klack, L. J. Qian, Y. P. Dong and B. Schartel, RSC Adv., 2017, 7, 720-728.

12 P. Y. Wen, X. M. Feng, Y. C. Kan, Y. Hu and R. K. K. Yuen, Polym. Degrad. Stab., 2016, 134, 202-210.

13 S. Q. Huo, J. Wang, S. Yang, J. P. Wang, B. Zhang, B. Zhang, X. Chen and Y. S. Tang, Polym. Degrad. Stab., 2016, 131, 106113.

14 B. Perret, B. Schartel, K. Stöß, M. Ciesielski, J. Diederichs, M. Döring, J. Krämer and V. Altstädt, Eur. Polym. J., 2011, 47, 1081-1089.

15 Y. Qiu, L. J. Qian, W. Xi and X. X. Liu, J. Appl. Polym. Sci., 2016, 133, 43214.

16 L. J. Qian, Y. Qiu, J. Y. Wang and W. Xi, Polymer, 2015, 68, 262-269.

17 P. Y. Wen, X. M. Feng, Y. C. Kan, Y. Hu and R. K. K. Yuen, Polym. Degrad. Stab., 2016, 134, 202-210.

18 T. S. Leu, J. Appl. Polym. Sci., 2006, 102, 2470-2480.

19 L. Zang, S. Wagner, M. Ciesielski, P. Müller and M. Döring, Polym. Adv. Technol., 2011, 22, 1182-1191.

20 S. Yang, J. Wang, S. Q. Huo, M. Wang and J. P. Wang, Polym. Degrad. Stab., 2015, 121, 398-406.

21 A. R. Horrocks, G. Smart, S. Hörold, W. Wanzke, E. Schlosser and J. Williams, Polym. Degrad. Stab., 2014, 104, 95-103.

22 X. Han, J. Q. Zhao, S. M. Liu and Y. C. Yuan, $R S C A d v ., 2014$, 4, 16551-16560.

23 F. Samyn and S. Bourbigot, Polym. Degrad. Stab., 2012, 97, 2217-2230.
24 B. Zhao, L. Chen, J. W. Long, H. B. Chen and Y. Z. Wang, Ind. Eng. Chem. Res., 2013, 52, 2875-2886.

25 B. Harald, K. Werner, S. Martin and W. Norbert, US Pat., 7635785, 2009-12-22.

26 N. Weferling and H. P. Schmitz, US Pat., 6242642, 2001-0605.

27 E. Schlosser, B. Nass and W. Wanzke, US Pat., 6255371, 200107-03.

28 E. Jenewein, H. J. Kleiner and W. Wanzke, US Pat., 6365071, 2002-04-02.

29 N. Weferling, H. P. Schmitz and G. Kolbe, US Pat., 6534673, 2003-03-18.

30 W. Yang, L. Song, Y. Hu, H. D. Lu and R. K. K. Yuen, Composites, Part B, 2011, 42, 1057-1065.

31 U. Braun and B. Schartel, Macromol. Mater. Eng., 2008, 293, 206-217.

32 T. Orhan, N. A. Isitman, J. Hacaloglu and C. Kaynak, Polym. Degrad. Stab., 2011, 96, 1780-1787.

33 J. Y. Wang, L. J. Qian, B. Xu, W. Xi and X. X. Liu, Polym. Degrad. Stab., 2015, 122, 8-17.

34 J. Yu, M. L. Li, Y. Yu, Y. J. Gao, J. C. Liu and F. Sun, Phosphorus, Sulfur Silicon Relat. Elem., 2015, 190, 1958-1970.

35 X. Z. Shao, L. S. Wang, M. Y. Li and D. M. Jia, Thermochim. Acta, 2012, 547, 70-75.

36 M. Jimenez, N. Lesaffre, S. Bellayer, R. Dupretz, M. Vandenbossche, S. Duquesne and S. Bourbigot, RSC Adv., 2015, 5, 63853-63865.

37 J. Y. Liu, J. Chen, X. Q. Liu, S. Sun and S. J. Cai, Fire Mater., 2014, 38, 155-165.

38 X. Q. Liu, J. Y. Liu and S. J. Cai, Polym. Compos., 2012, 33, 918-926.

39 Z. Hu, L. Chen, G. P. Lin, Y. Luo and Y. Z. Wang, Polym. Degrad. Stab., 2011, 96, 1538-1545.

40 S. Brehme, B. Schartel, J. Goebbels, O. Fischer, D. Pospiech, Y. Bykov and M. Döring, Polym. Degrad. Stab., 2011, 96, 875884.

41 U. Braun, B. Schartel, M. A. Fichera and C. Jager, Polym. Degrad. Stab., 2007, 92, 1528-1545.

42 A. Lorenzetti, M. Modesti, E. Gallo, B. Schartel, S. Besco and M. Roso, Polym. Degrad. Stab., 2012, 97, 2364-3269.

43 J. Y. Wang, L. J. Qian, Z. G. Huang, Y. Y. Fang and Y. Qiu, Polym. Degrad. Stab., 2016, 130, 173-181.

44 Y. Y. Fang, L. J. Qian and Z. G. Huang, Polym. Int., 2017, 66, 719-725. 